\title{
CORPO-ORALIDADES \\ TEXTURAS POÉTICAS DO CORPO OBSCENO, TRADIÇÃO E RENOVAÇÃO NAS DANÇAS POPULARES DA BAHIA
}

Cíntia Paula Lopez (UFBA)

As danças tradicionais na Bahia têm significativa reverberação quanto ao modo com que os olhares se voltam para aquele local, implicando exotismos que não contemplam a efervescência dos ambientes que as produzem. Este artigo sugere o exercício de ampliação das perspectivas desse olhar para as tradições e para o corpo em configurações móveis que cumprem o papel de dinamizar e renovar esses repertórios.

DANÇAS POPULARES; ORALIDADE; TRADIÇÃO; CORPO.

LOPEZ, Cíntia Paula. Corpo-oralidades: texturas poéticas do corpo obsceno, tradição e renovação nas danças populares da Bahia. Textos escolhidos de cultura e arte populares, Rio de Janeiro, v.10, n.1, p. 133-140, mai. 2013. 


\section{CORPO-ORALITIES}

POETIC TEXTURES OF THE OBSCENE BODY, TRADITION AND RENEWAL IN FOLK DANCES OF BAHIA

Cíntia Paula Lopez (UFBA)

Traditional dances in Bahia have significant reverberation as the way the eyes are on that site, implying an exoticism that does not include the effervescence of the environments in which they are produced. This article suggests broadening the perspectives that look at the traditions and the body in mobile configurations that fulfill the role to stimulate and renew these repertoires.

FOLK DANCES; BODY; ORALITY; TRADITION.

LOPEZ, Cíntia Paula. Corpo-oralidades: texturas poéticas do corpo obsceno, tradição e renovação nas danças populares da Bahia. Textos escolhidos de cultura e arte populares, Rio de Janeiro, v.10, n.1, p. 133-140, mai. 2013. 
No Estado da Bahia é recorrente o pensamento das "tradições"; o baiano é educado, desde pequeno, a se pensar como pertencente a um espaço que contém "a origem" das tradições afro no Brasil. Nada de tão grave nisso, não fosse a utilização desse lema como desculpa para a discriminação por meio de mecanismos políticos e mercadológicos de exploração dos bens culturais locais e a consequente deformação nos processos de produção, replicando antigos julgamentos que isolam produções "nobres" das "baixas". ${ }^{1}$

Para ser mais específica aponto, em primeiro lugar, para a miopia que a afirmativa acima carrega ao desconsiderar o caráter dinâmico da cultura, em constante construção, e as múltiplas contribuições culturais que alimentam essas dinâmicas.

Neste artigo proponho uma breve reflexão a partir do olhar para a dança e para os complexos culturais que a englobam nos fazeres da cultura popular baiana, como o samba de roda, o carnaval, as serestas e os pagodes. Solicito, portanto, ao leitor o desafio de desarmar os preconceitos que acompanham esses eventos (por mais relevantes que sejam as razões para tal julgamento), no intuito de demonstrar sua importância para a renovação e memória de textos ${ }^{2}$ como o samba de roda.

É comum para a lida com artefatos da cultura, por parte de braços políticos, sua categorização em "prateleiras", pressupondo hierarquização entre eles. Mesmo que não explícita nos enunciados de editais, podemos percebê-la claramente no reconhecimento do samba de roda como Patrimônio Imaterial da Humanidade (SANDRONI, 2004) ou na verba destinada pelo governo para a realização de festas de largo ou para o carnaval; em momento nenhum, porém, se cogita sequer a coexistência desses eventos com dinâmicas espontâneas, necessárias e sempre presentes, como os pagodes, o arrocha, entre outros.

Longe de querer, com esta pequena discussão, condenar ações de políticas afirmativas em relação à cultura popular, proponho aqui apenas alguns questionamentos quanto à maneira de olhar para esses eventos carregados do exotismo da "legitimidade" e da "pureza étnica", e por outro lado contribuir para que esse olhar seja mais eficaz na construção de políticas que contemplem seu caráter dinâmico e multirrelacional entre produções vizinhas e intercambiantes.

Ao participar de uma festa de largo em Salvador, no Estado da Bahia, fica clara a variedade de combinações com as quais o argumento de determinada celebração se mescla. Podemos tomar como exemplo a festa de Nosso Senhor do Bonfim $^{3}$ (como poderia ser a de santa Bárbara ou a de lemanjá); ainda que a tradição da festa se mantenha, ou seja, o caráter essencialmente religioso, católico em sua essência, não descarta de sua programação a coexistência do profano e 
do sagrado (este último, múltiplo, pois o candomblé não deixa de ser festejado a partir do sincretismo) no mesmo espaço.

Jocélio Teles dos Santos, citado por Döring (2002, p. 20), através de vários documentos de legislação sobre a perseguição e condenação dos batuques em meados do século XIX, comenta as razões e os locais para esses ajuntamentos:

No decorrer do século (XIX) o termo batuque foi geralmente utilizado para estas reuniões em lugares tradicionais dos africanos e seus descendentes que ali trabalhavam, como também nas festas religiosas católicas que tradicionalmente festejam a parte profana com a participação das músicas e danças dos negros, que no olhar das autoridades feriam o bom senso da civilização.

Ainda hoje, se nas procissões e na comissão de frente o sagrado predomina conduzindo o festejo, no entorno e logo nas partes que se seguem é possível identificar diversos microuniversos de diferentes formas de participação ambivalentes, e por que não multivalentes, percebidas na venda e no consumo de bebidas alcoólicas, nas rodas de samba ou de candomblé que se organizam ao longo do caminho, assim como pequenas serestas que duram até muito depois de toda a celebração oficial terminar. É para esse caminho considerado "ruído" que proponho aqui uma atenção especial.

As denúncias comuns atribuídas aos pagodes ou serestas destacam a sensualidade ou obscenidade neles contidas, como argumento para os rótulos de "baixos", "pobres" e, ainda, como se fossem novidade seus modos de elaboração, apontando para um rumo decadente que a cultura estaria tomando. Seriam realmente novas essas formas de expressão? Seria seu caráter ousado uma das razões para a acusação de "mácula" das tradições baianas?

Encontramos numerosos registros de relatos que demonstram, desde meados do século XIX, a presença incontestável de elementos obscenos e lascivos tanto nas letras das canções improvisadas como nos modos de dançar dos negros em aglomerações em espaços públicos, tomando parte em festas religiosas católicas ou nas proximidades de locais de trabalho, como portos, mercados ou praças da cidade de Salvador. Por muito tempo significaram justificativa para prisões e proibições de batuques e sambas, mas dificilmente se registra na memória o link de que pode ser justamente um dos traços mais expressivos ainda presente em outros modos de arranjos sociais e de entretenimento, e, ao mesmo tempo, elemento significativo para a coesão entre grupos de escravos provenientes de nações originalmente inimigas na África.

O círculo se fechava e o tocador de viola sentava-se num dos cantos, e começava uma simples toada, acompanhada por algumas 
canções favoritas, repetindo o refrão, e frequentemente um dos versos era improvisado e continha alusões obscenas. Um homem ia para o centro da roda e dançava minutos, tomando atitudes lascivas, até que escolhia uma mulher que avançava, repetindo os meneios não menos indeentes. $E$ esse divertimento durava às vezes até o amanhecer (RUGENDAS apud DÖRING, 2002, p.15)

Como podemos observar nessa narração, na voz do viajante Koster em 1813, em Recife e citada por Rugendas, já no início do século XIX estavam presentes nas ruas e em espaços públicos, traços de "obscenidade", "lascividade" e "indecência", tanto nas letras das músicas como nas formas de dançá-las. Fato esse que evidencia que não é exclusividade de configurações atuais, nem tampouco novidade essa prática.

Sem tomar a posição de julgar a "oficialidade" dessas práticas, apenas penso ser impossível desconsiderar sua coexistência e sua condição imprescindível para a manutenção de outras produções vizinhas, como o samba de roda, os carnavais, entre outras.

Na pesquisa sobre o samba de roda na Ilha de Itaparica que realizei durante o mestrado me deparei com algumas situações incômodas o suficiente para que continuasse buscando direções a seguir. Ao iniciar a coleta de dados em campo conheci o grupo de samba de roda intitulado Unidos do Samba da Misericórdia, liderado por dona Amália Moreira ${ }^{4}$ e formado por mulheres marisqueiras e agricultoras em sua maioria. Incentivadas pela Secretaria de Turismo local através do pagamento de cachês e patrocínios para confecção de figurinos elas faziam apresentações em festas oficiais produzidas pela Secretaria. A questão aqui foi, em primeiro lugar, a imposição por parte da Secretaria dos modelos de figurinos que deveriam ser elaborados e utilizados, ou seja, de "baiana" e as formas pelas quais o grupo deveria se organizar juridicamente para ter acesso às verbas de editais a eles destinados, burocratizando-se e obtendo o cadastro nacional de pessoa jurídica (CNPJ).

Ao prosseguir a pesquisa, conhecendo outros grupos "não oficiais", tive a oportunidade de ouvir relatos de sambadoras antigas e de constatar o caráter informal e familiar das rodas de samba naquele local e a total ausência de qualquer tipo de "figurino". Dona Amália Moreira, em uma das visitas registradas fez questão de me apresentar o figurino preferido pelo grupo e só utilizado em apresentações informais, confeccionado em lycra, com saias curtas e blusas de alças, justificando que o local é muito quente para as tradicionais roupas pesadas de baianas. 
Solicito aqui atenção para os processos da cultura em detrimento de sua aparente forma. Em diversos aspectos é senso comum captar uma configuração a partir de seu formato, ou seja, modelos como a "baiana de candomblé", são cristalizados e referenciados em vez de se atentar para as lógicas que organizam esses arranjos. As situações geram configurações a cada espaço/tempo e estão relacionadas, e não submetidas a fatores móveis. O grande temor de rompimento com o tradicional, portanto, não procede quando consideramos seu caráter instável e transitório, que busca permanência viva e com diferentes arranjos.

Como um dos fatores relevantes nesses processos, ainda é possível destacar a constante construção de estratégias de sobrevivência na lida com as tensões em regiões de fronteira, ou seja, são evocados recursos da memória cultural de determinado grupo, combinados com novas informações pinçadas aqui e ali, podendo citar desde o acesso a verbas que viabilizem sua manutenção enquanto grupo até a apreensão do uso de novas tecnologias. Em qualquer desses casos o que está em jogo é a garantia das mencionadas permanência e "estabilidade". Quero dizer com isso, de acordo com o que o semioticista luri Lotman chama de elipticidade semiótica, ${ }^{5}$ que cada texto da cultura se conserva em constante renovação para que possa seguir existindo e, ainda mais, essa renovação se dá a partir da mediação entre o que já existia com o que chega de novo, no intuito de estabilizar as tensões geradas a cada encontro (ou choque). Nesse sentido, aquilo que muitas vezes é visto como ruído ou sujeira para configurações tradicionais da cultura pode constituir justamente fatores que sustentam e cumprem o papel de alimentar e dinamizar a memória desses grupos.

Considerando a ideia do corpo como agente fundamental nos processos de cognição e apreensão do mundo, proponho que ele seja entendido aqui como atuante das operações de transmissão e manutenção dessas memórias culturais dos grupos. Como apontam Christine Greiner e Helena Katz em sua prototeoria Corpomídia, o corpo é visto como responsável pelas seleções e sínteses dos processos comunicacionais do ambiente ou, ainda, como matriz cognitiva, e a "dança como uma especialização que trabalha basicamente como movimento metafórico" (GREINER, 2005). Segundo essa autora:

Para Hutchins, cultura é sempre processo e tem lugar tanto dentro como fora das mentes das pessoas. A sua proposta é, portanto, a de que o principal componente da cultura seja mesmo o processo cognitivo. A cognição, por sua vez, seria sempre um processo cultural. Portanto, aquilo que costumamos estudar como as "coisas" da cultura, tornam-se os resíduos do processo (p. 103) 
Entre as decorrências dessa visão poderíamos pensar em uma corpo-oralidade, lida como possível poética do corpo que, em vez de cristalizar esses eventos, tece a cada tempo novas narrativas, sem excluir as antigas, contemplando seu caráter dinâmico de renovação e atualização constantes. Cabe aqui, portanto, pensar nesse corpo como operador das metáforas do universo pessoal de cada indivíduo. Uma vez que consideramos esse corpo pensante, podemos deslocar consideravelmente nosso olhar para os enredos de suas narrativas.

Retomando a ideia inicial do presente artigo, as margens ou todas aquelas produções circundantes que comumente são vistas como ruídos em grandes festas populares podem ser consideradas fundamentais para sua existência. A velocidade com que elas se renovam e se modificam pode ser um dos fatores para seu poder de comunicação e consequente repercussão no agrupamento de pessoas em festas populares.

\section{REFERÊNCIAS BIBLIOGRÁFICAS}

DOMENICl, Eloisa. A experiência corpórea como fundamento da comunicação. Tese (Doutorado). Programa em Comunicação e Semiótica, Pontifícia Universidade Católica de São Paulo, São Paulo, 2004.

DÖRING, Katharina. O samba de roda do Sembagota: tradição e contemporaneidade. Dissertação (Mestrado). Escola de Música da Universidade Federal da Bahia. Salvador, 2002.

GREINER, Christine. O corpo: pistas para estudos indisciplinares. São Paulo: Annablume, 2005.

LOTMAN, Iuri. La semiótica de la cultura y el concepto de texto. In La Semiosfera I: semiótica de la cultura y del texto. Madrid: Editora Cátedra, 1996.

LOTMAN, Iuri. La memoria a la luz de la culturologia. In La Semiosfera I: semiótica de la cultura y del texto. Madrid: Editora Cátedra, 1996.

SANDRONI, Carlos. Dossiê de Candidatura do Samba de Roda do Recôncavo Baiano: para a terceira proclamação das obras primas do patrimônio oral e imaterial da humanidade. Brasília: Unesco, 2004.

\section{NOTAS}

1 No segundo semestre de 2011 a deputada estadual da Bahia Luíza Maia propôs o projeto de lei 19.237/2011 que veda a utilização de recursos públicos para a contratação de artistas que, em suas composições (músicas, danças ou coreografias) desvalorizem, incentivem a violência ou exponham as mulheres a situação de constrangimento. A questão aqui é quanto aos critérios utilizados pelo Estado para tal julgamento e o poder por ele utilizado nessa censura para produções culturais. 
20 conceito de texto aqui é utilizado com o sentido proposto pelo semioticista Iuri Lotman: que um termo ao carregar em si a capacidade semântica de desdobrar-se em mais de um sentido simultaneamente pode ser considerado um texto da cultura.

3 Festa popular que acontece na segunda quinta-feira de janeiro partindo da Igreja de Nossa Senhora da Conceição da Praia e seguindo em procissão com a lavagem ritual, por parte de baianas de candomblé, até a Igreja de Nosso Senhor do Bonfim, ambas em Salvador (BA).

4 Amália Moreira Mota é agricultora e coordenadora do grupo de samba Unidos do Samba da Misericórdia, Itaparica (BA).

5 Elipticidade semiótica, para Lotman (1996), é um mecanismo atuante nos processos de produção e manutenção de textos da cultura. Na transposição de um texto para outro contexto, cria-se uma lacuna que é imediatamente preenchida ao entrar em contato com outros textos, gerando outros sentidos.

Cíntia Paula Lopez é mestre em dança pela UFBA (2009) e professora de dança em Salvador (BA).

Recebido em: 02/10/2012

Aceito em: 19/04/2013 